\title{
PSYCHIATRIC JOKES AND THEIR IMPLICATIONS
}

)

BY Dr M. F. Hussain

Consultant Psychiatrist, St Augustine's Hospital, Canterbury

'Lite is a comedy to those who think and a tragedy to those who feel' reflects the widespread belief in the importance of humour. It presents in a variety of guises in psychiatric jokes.

The root of laughter may be the triumph over other people or circumstances, mockery and ridicule. Laughter at the foolish actions of others is central to human experience.

It was decided to ask a computèr if there was a God. It was fed with the Bible, the Koran, and all documents relating to every creed, every philosophical argument for and against. It trundled away for a whole week and came up with the answer, 'There is now!'

Humour may arise from incongruous pairing of ideas or situations that are divergent from habitual customs.

A man took his dog to the vet with the request could he chop off the dog's tail? 'That's a nasty thing to do' replied the vet demanding explanation for this brutality. 'I had a letter today about the mother-inlaw coming for a visit and we don't want any sign of welcome', was the reply.

Some jokes convey reservations about the value of psychiatric treatment and the fibre and status of its practitioners. "Anybody who wants to go to a psychiatrist needs to have his head examined'. 'When two psychiatrists meet in the street the one says to the other "I know that you are feeling fine, but how am I?".'

Other jokes indicate suspicion, even malice, towards the profession and the feeling that it is greedy. A man rushed in to a psychiatrist's consulting room saying he thought he had a 'split personality'. 'All right' said the psychiatrist, 'That'll be ten pounds each'.

A man goes to a psychiatrist complaining of his dominating mother. The psychiatrist asks him to describe a typical day.

'I got up, had breakfast... '

'What did you have for breakfast?'

'Just coffee!'
Explodes the psychiatrist, 'You call that breakfast?'

Here the psychiatrist confuses the man further as regards his ambivalent feelings by behaving just like the patient's mother. The joke shows that many people are afraid that a relationship with a psychiatrist will be too much like that with their parents for comfort.

On similar lines-'I've become impossible to live with doctor', admitted the patient, 'my wife has left me and her family have studiously avoided me for years'. The psychiatrist leaned forward with keen professional interest. 'Tell me', he said, 'how did you manage that?'

In other settings psychatric humour performs the function of giving relief from excessive tension.

An anxious patient, whose psychiatrist failed to diagnose his complaint, watched fascinated as the details were fed into a computer. The patient and the psychiatrist chatted while the machine rattled and banged. Finally it printed on the card. The patient, tense with excitement and suspense, asked 'What does it say doctor?' 'It says', replied the psychiatrist, squinting hard at the card, 'that there is a lot of it about'.

Other jokes imply that the labelling of actions by psychiatrists solves a problem when no true solution exists.

A patient told her psychiatrist that she could not resist picking things up in shops and putting them in her pocket. 'Don't worry' said the psychiatrist, 'I've sorted out your problem straight away, you're a thief.'

That slips of the tongue can not only be humorous but revealing was emphasized by Freud. In his Psychopathology of Everyday Life he gives an example of a lady who advanced the following opinion at a social gathering:

'Yes a woman must be pretty if she is to please men. A man is much better; as long as he has five straight limbs he needs nothing more.'

This suggests condensation and contamination of two turns of phrase with similar meanings:

As long as he has his four limbs straight.

As long as he has five wits about him. 